\title{
Fatigue life and early cracking predictions of extruded AZ31B magnesium alloy using critical plane approaches
}

\author{
Fábio Castro $^{a}$, Yanyao Jiang ${ }^{\text {b,* }}$ \\ a Department of Mechanical Engineering, University of Brasilia, 70910-900 Brasilia, DF, Brazil \\ ${ }^{b}$ Department of Mechanical Engineering, University of Nevada, Reno, NV 89557, USA \\ Phone 775-784-4510, Fax 775-784-1701, E-Mail yjiang@unr.edu
}

${ }^{*}$ To whom correspondence should be addressed.

\begin{abstract}
The Smith-Watson-Topper (SWT) criterion, the Fatemi-Socie criterion, and the Jiang criterion were evaluated based on the experimentally observed cracking behavior and fatigue life of an extruded AZ31B magnesium alloy. The fatigue experiments were performed on thin-walled tubular specimens subjected to tension-compression, torsion, and combined axial-torsion loading. The SWT criterion fails to correlate the tension-compression and torsion baseline experiments. The Fatemi-Socie criterion predicts well the fatigue lives for all experiments, but the criterion yields a less satisfactory prediction of the cracking behavior for most of the tests. The difficulty of the SWT and Fatemi-Socie criteria in correlating the observed cracking orientations is attributed to the mixed cracking behavior of the material. The Jiang criterion provides a reasonable description of the cracking behavior and fatigue life predictions. A discussion on the current capability of the critical plane approaches to predict the fatigue behavior of wrought magnesium alloys is presented, and further studies are recommended.
\end{abstract}

Keywords: Magnesium alloy; Multiaxial fatigue; Critical plane approach; Fatigue life; Cracking orientation

\section{Introduction}

Magnesium (Mg) alloys are increasingly been used in the transportation industries due to their attractive properties such as low density, high specific strength, and excellent machinability. Most of the current applications make use of cast components without significant structural functions. In recent years, however, wrought $\mathrm{Mg}$ alloys have emerged as potential candidates for structural applications [1,2]. One of the advantages of wrought $\mathrm{Mg}$ alloys compared with their casting counterparts is the superior mechanical properties due to the absence of casting defects [3-6]. In this scenario, a knowledge of the fatigue behavior of wrought $\mathrm{Mg}$ alloys is of key importance, as failure due to fatigue is critical in cyclically loaded components. The current understanding of the 
fatigue behavior of wrought $\mathrm{Mg}$ alloys has mainly derived from uniaxial tests (see, for instance, [7-11] and references therein). Although these studies are of fundamental importance, structural components often experience multiaxial loading histories. Despite the importance of the subject, very limited work [12-17] has been carried out on the multiaxial fatigue behavior of wrought $\mathrm{Mg}$ alloys. The existing multiaxial fatigue experiments are limited to a few types of magnesium alloys, stress states, and loading histories.

Bentachfine and co-workers [12,13] conducted strain-controlled axial-torsional fatigue experiments on magnesium-lithium alloy. In-phase and out-of-phase tests were carried out using identical axial and shear strain amplitudes $(0.5 \%$ and $0.75 \%$, respectively). It was found that the fatigue live depended on the out-of-phase angle with the minimum lives occurring for phase differences between $60^{\circ}$ and $120^{\circ}$ and the maximum live for in-phase loading. Yu et al. [14] carried out multiaxial fatigue tests on thin-walled tubes made of an extruded AZ61 A Mg alloy. In-phase and $90^{\circ}$ out-of-phase axial-shear strain histories were investigated. The equivalent strain amplitude-life curves for these loading paths clearly indicated a significant decrease in fatigue life as a result of out-of-phase straining. It was found that the modified Smith-Watson-Topper (SWT) fatigue criterion [18] could predict fatigue life well. Life predictions based on the Fatemi-Socie criterion [19] also provided satisfactory correlations, except in the high-cycle fatigue regime. Xiong et al. [15] investigated the multiaxial fatigue behavior of an extruded AZ31B Mg alloy. The experimental procedure was similar to that employed by $\mathrm{Yu}$ et al. [14]. It was observed that nonproportional straining had a detrimental effect on fatigue live when compared with proportional tests with identical equivalent strain amplitudes. In addition, it was found that reasonable multiaxial fatigue life estimates could be obtained using a modified SWT criterion and the Jiang fatigue criterion [20]. Albinmousa and Jahed [16,17] carried out multiaxial fatigue tests on thin-walled tubes machined from an AZ31B extruded profile. The specimens were subjected to combined axial-torsional loading with phase angles of $0^{\circ}, 45^{\circ}$ and $90^{\circ}$, respectively. The observed fatigue lives were satisfactorily correlated using the Fatemi-Socie critical plane criterion and an energy based criterion [21]. The multiaxial version of the SWT criterion [22] yielded a good correlation of the test data, except for the fully reversed torsion tests [16] and a few $90^{\circ}$ outof-phase tests [17].

The current work investigates the feasibility of using existing critical plane approaches for the prediction of the fatigue behavior of an extruded AZ31B Mg alloy. New multiaxial fatigue experimental results as well as test data reported earlier [17] were employed in the study. Three critical plane fatigue criteria, namely, the SWT criterion [22], the Fatemi-Socie criterion [19], and the Jiang criterion [20], were evaluated for their capabilities to estimate both the cracking behavior and the fatigue life of the material. A general discussion on the multiaxial fatigue models for $\mathrm{Mg}$ alloys is presented, and further studies are recommended. 


\section{Material and fatigue experiments}

A commercial AZ31B Mg alloy supplied in the form of extruded round bars was used in the current study. The material has a chemical composition in weight percentage of 2.5-3.5 Al, 0.71.3 $\mathrm{Zn}, 0.2 \mathrm{Mn}, 0.3 \mathrm{Si}, 0.05 \mathrm{Cu}, 0.005 \mathrm{Ni}, 0.005 \mathrm{Fe}$, and $\mathrm{Mg}$ as balance. No heat treatment was carried out on the extruded bars. The initial microstructure measured by electron backscatter diffraction (EBSD) is shown in Fig. 1. The extrusion, radial, and tangential (hoop) directions are referred to as $\mathrm{ED}, \mathrm{RD}$, and $\mathrm{TD}$, respectively. The grain structure contains both fibrous grains elongated along the extrusion direction and equiaxed grains on the plane perpendicular to the extruded direction. The width of the elongated grains ranges from approximately $2 \mu \mathrm{m}$ to $15 \mu \mathrm{m}$. The average grain size of the equiaxed grains on the plane perpendicular to the extruded direction is approximately $90 \mathrm{um}$. No twins were detected in the initial microstructure.

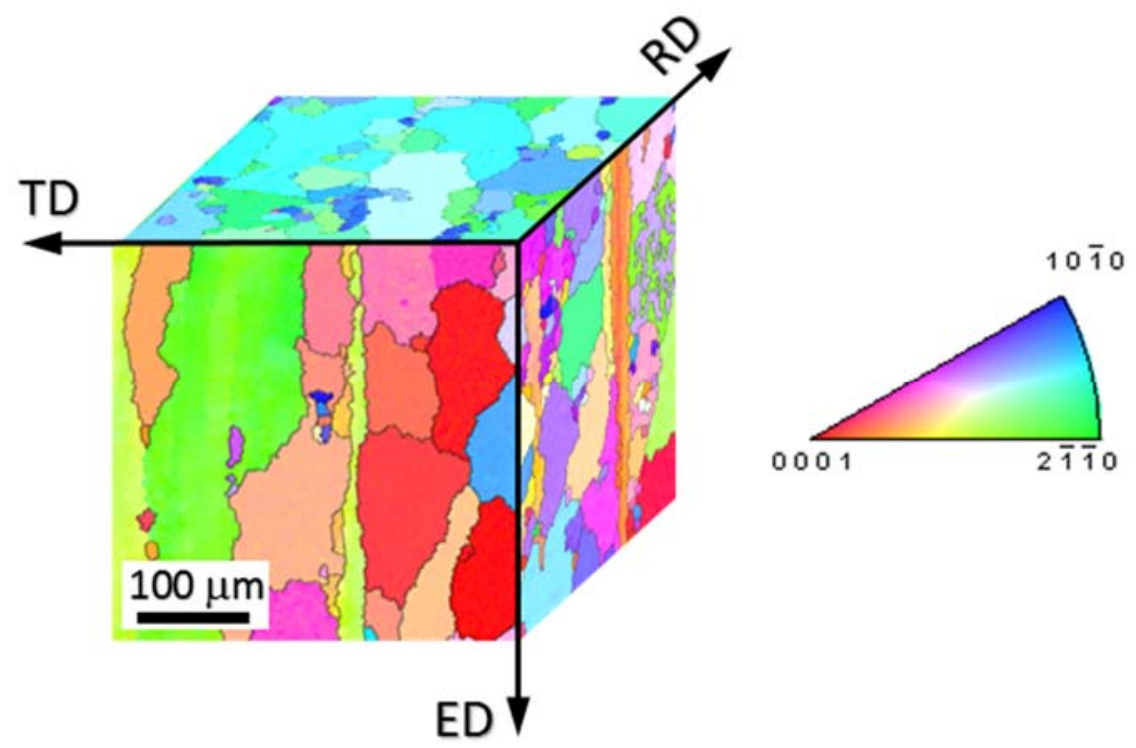

Figure 1. Initial microstructure of the extruded AZ31B measured by EBSD.

Tubular specimens identical to those used in an early study [15] were machined with their longitudinal axes parallel to the extrusion direction of the bars. The inner and outer diameters in the gage section of the specimen were $20 \mathrm{~mm}$ and $24 \mathrm{~mm}$, respectively. The outer surface of the gage section was polished using silicon carbide papers with grit numbers ranging from 400 to 1200. After polishing, the surfaces were examined under a light microscope to ensure the machining marks were completely removed. Both static and fatigue experiments were conducted using a servohydraulic tension-torsion testing machine. Testing frequencies for the fatigue experiments varied from 0.1 to $10 \mathrm{~Hz}$ depending on the loading amplitude. All the experiments were conducted in ambient air. Fatigue life was defined as the moment when the maximum axial/shear stress in a loading cycle dropped by $5 \%$ from the stabilized or peak value, or when a crack was visible on the outer surface of the specimen. In most of the cases, a macroscopic surface crack was detected at the end of the test. 
During each fatigue experiment, the axial and shear strains on the outer surface of the specimen were directly measured with a biaxial extensometer, while the axial force and the torque applied to the specimen were measured with the load cells of the machine. At each predefined loading cycle, the strains, the axial force, and the torque were recorded for a minimum of 200 data points. The axial and shear stresses were determined from the measured loads and the cross-section dimensions. In the calculation procedure, the axial and shear stresses were assumed to be uniformly distributed through the wall of the specimen. In addition, the cross-section dimensions during the test were corrected considering both the elastic deformation and the plastic deformation incompressibility. The loading paths used in the fatigue tests are shown in Fig. 2. Paths I and II refer to fully reversed tension-compression and torsion loadings, respectively. Paths III and IV designate proportional and $90^{\circ}$ out-of-phase loadings, respectively. Path V is a $90^{\circ}$ out-of-phase straining with a mean axial strain. The strain amplitudes in Paths IV and $\mathrm{V}$ have the following relationship: $\Delta \gamma / 2=\sqrt{3} \Delta \varepsilon / 2$ where $\Delta \gamma / 2$ is the shear strain amplitude and $\Delta \varepsilon / 2$ is the axial strain amplitude. Path VI comprises proportional straining containing the origin and restricted to a specific quadrant of the $\varepsilon-\gamma / \sqrt{3}$ plane. For this loading case, strain paths in the first and fourth quadrants were generated by varying the angle $\alpha$ from $-22.5^{\circ}$ to $67.5^{\circ}$. Path VII was obtained under fully reversed shear strain with a superimposed static axial stress ranging from $150 \mathrm{MPa}$ to $-100 \mathrm{MPa}$.
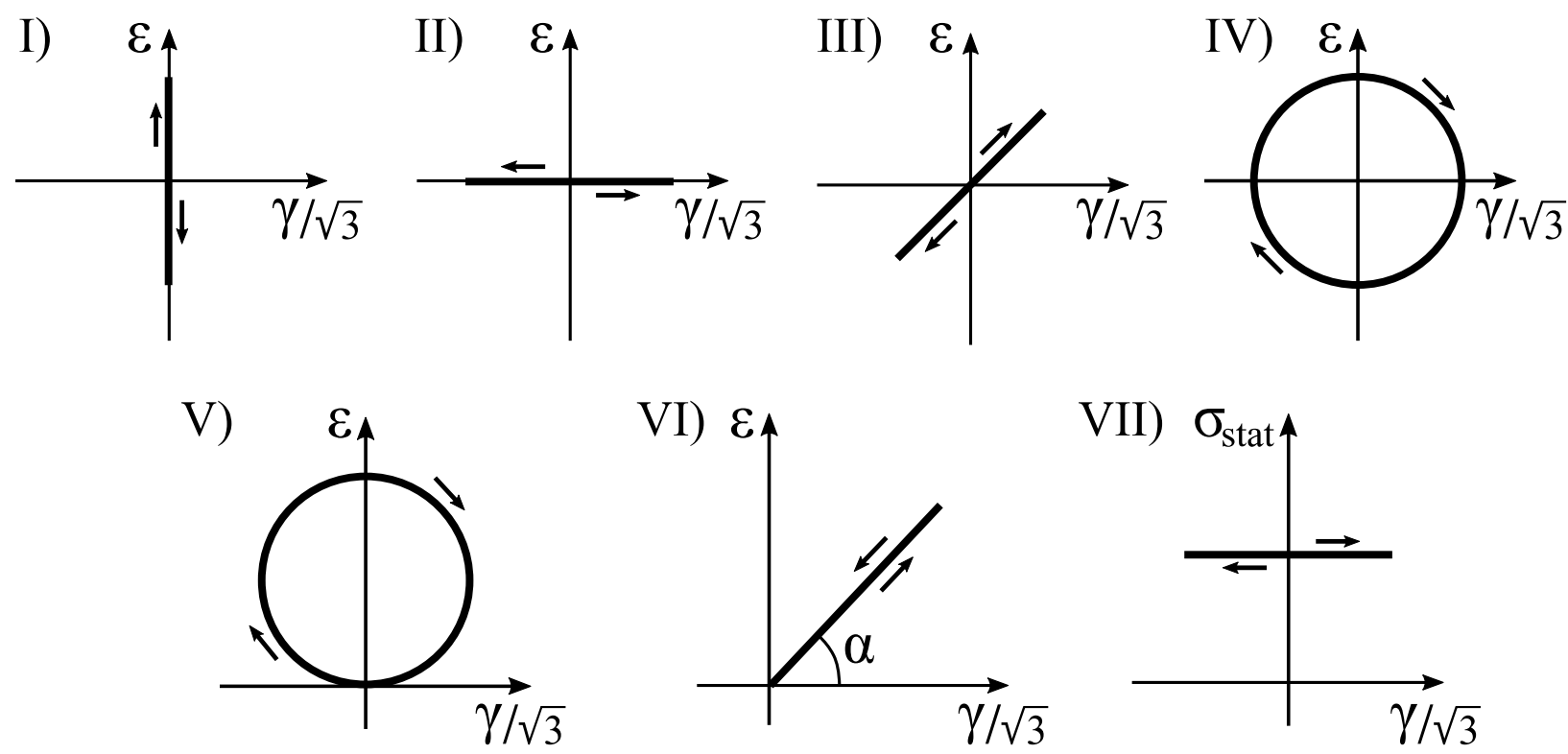

Figure 2. Loading paths used in the fatigue tests.

For the sake of completeness, the static properties of the material reported earlier [15] are listed in Table 1. The fatigue results are summarized in Table 2. The stress amplitudes and mean stresses listed in Table 2 were determined from a stress-strain hysteresis loop at approximately $50 \%$ of the fatigue life. The test data corresponding to Paths I-IV were taken from previously published work [15]. 
Table 1. Static material properties of extruded AZ31B Mg alloy [15].

\begin{tabular}{ll}
\hline Elasticity modulus, $E$ & $44.8 \mathrm{GPa}$ \\
Shear modulus, $G$ & $16.9 \mathrm{GPa}$ \\
$0.2 \%$-offset yield stress in tension, $\sigma_{\mathrm{yt}}$ & $244 \mathrm{MPa}$ \\
$0.2 \%$-offset yield stress in compression, $\sigma_{\mathrm{yc}}$ & $151 \mathrm{MPa}$ \\
Ultimate strength under tension, $S_{\mathrm{ut}}$ & $298 \mathrm{MPa}$ \\
Ultimate strength under compression, $S_{\mathrm{uc}}$ & $417 \mathrm{MPa}$ \\
Fracture stress under tension, $\sigma_{\mathrm{ft}}$ & $338 \mathrm{MPa}$ \\
Elongation under tension, $e_{\mathrm{ft}}$ & 0.105 \\
Elongation under compression, $e_{\mathrm{fc}}$ & 0.093 \\
Reduction in area under tension, $R A$ & $12 \%$ \\
\hline
\end{tabular}

Table 2. Fatigue test data for extruded AZ31B Mg alloy.

\begin{tabular}{|c|c|c|c|c|c|c|c|c|}
\hline $\begin{array}{l}\text { Load } \\
\text { path }\end{array}$ & $\begin{array}{c}\text { Specimen } \\
\text { ID }\end{array}$ & $\begin{array}{l}\Delta \varepsilon / 2 \\
(\%)\end{array}$ & $\begin{array}{c}\sigma_{\mathrm{m}} \\
(\mathrm{MPa})\end{array}$ & $\begin{array}{c}\Delta \sigma / 2 \\
(\mathrm{MPa})\end{array}$ & $\begin{array}{c}\Delta \gamma / 2 \\
(\%)\end{array}$ & $\begin{array}{c}\tau_{\mathrm{m}} \\
(\mathrm{MPa})\end{array}$ & $\begin{array}{r}\Delta \tau / 2 \\
(\mathrm{MPa})\end{array}$ & $\begin{array}{r}N_{\mathrm{f}} \\
\text { (cycles) }\end{array}$ \\
\hline \multirow{13}{*}{ I } & 31BTU83 & 2.00 & 33.5 & 225.5 & & & & 110 \\
\hline & 31BTU40 & 1.00 & 57.9 & 222.8 & & & & 320 \\
\hline & 31BTU84 & 1.00 & 58.3 & 207.1 & & & & 250 \\
\hline & 31BTU81 & 0.75 & 47.4 & 221.9 & & & & 720 \\
\hline & 31BTU41 & 0.50 & 42.3 & 193.0 & & & & 2,660 \\
\hline & 31BTU82 & 0.50 & 72.9 & 196.2 & & & & 2,180 \\
\hline & 31BTU46 & 0.47 & 44.1 & 186.2 & & & & 2,620 \\
\hline & 31BTU03 & 0.45 & 17.1 & 174.7 & & & & 11,360 \\
\hline & 31BTU02 & 0.40 & 22.6 & 164.9 & & & & 14,560 \\
\hline & 31BTU47 & 0.35 & 13.8 & 147.7 & & & & 29,900 \\
\hline & 31BTU01 & 0.30 & -2.0 & 127.6 & & & & 75,840 \\
\hline & 31BTU43 & 0.26 & 2.2 & 114.3 & & & & 160,400 \\
\hline & 31BTU09 & 0.24 & 0.1 & 103.2 & & & & $>1,185,000$ \\
\hline \multirow{9}{*}{ II } & 31BTU19 & & & & 2.42 & 0.2 & 102.5 & 44 \\
\hline & 31BTU12 & & & & 1.73 & 0.4 & 94.6 & 80 \\
\hline & 31BTU06 & & & & 1.3 & 0.4 & 91.0 & 280 \\
\hline & 31BTU44 & & & & 1.04 & -0.06 & 78.5 & 963 \\
\hline & 31BTU08 & & & & 0.87 & 0.2 & 74.9 & 2,120 \\
\hline & 31BTU04 & & & & 0.69 & 0.2 & 70.7 & 7,620 \\
\hline & 31BTU10 & & & & 0.53 & 0.5 & 60.5 & 24,520 \\
\hline & 31BTU31 & & & & 0.42 & 0.1 & 46.2 & 71,580 \\
\hline & 31BTU20 & & & & 0.35 & 0.4 & 50.6 & 556,020 \\
\hline \multirow{4}{*}{ III } & 31BTU21 & 1.00 & 28.5 & 175.3 & 1.73 & 3.8 & 75.5 & 294 \\
\hline & 31BTU14 & 0.71 & 41.2 & 177.3 & 1.23 & 5.2 & 66.3 & 460 \\
\hline & 31BTU22 & 0.50 & 23.1 & 162.0 & 0.92 & 4.1 & 69.4 & 1,420 \\
\hline & 31BTU30 & 0.42 & 20.1 & 148.6 & 0.88 & 4.2 & 61.8 & 2,590 \\
\hline
\end{tabular}




\begin{tabular}{|c|c|c|c|c|c|c|c|c|c|}
\hline & 31BTU23 & 0.35 & 6.1 & 132.1 & 0.61 & 4.0 & 56.1 & & 5,360 \\
\hline & 31BTU42 & 0.28 & -0.4 & 112.4 & 0.49 & 2.3 & 52.6 & & 11,600 \\
\hline & 31BTU25 & 0.21 & -10.7 & 89.2 & 0.37 & 3.3 & 47.3 & & 49,679 \\
\hline & 31BTU48 & 0.18 & -8.2 & 78.7 & 0.32 & 3.1 & 43.7 & & 87,392 \\
\hline & $31 \mathrm{BTU} 29$ & 0.17 & -15.0 & 74.6 & 0.29 & 5.6 & 43.5 & & $>1,057,300$ \\
\hline \multirow{10}{*}{ IV } & 31BTU29e & 1.41 & 5.3 & 237.7 & 2.45 & -7.2 & 138.7 & & 35 \\
\hline & 31BTU11 & 1.00 & 9.4 & 201.2 & 1.73 & -5.9 & 117.7 & & 68 \\
\hline & 31BTU16 & 0.75 & 11.6 & 186.8 & 1.3 & -4.7 & 104.2 & & 180 \\
\hline & 31BTU13 & 0.50 & 18.8 & 166.9 & 0.87 & -5.1 & 84.5 & & 580 \\
\hline & 31BTU18 & 0.40 & 4.0 & 144.7 & 0.69 & -1.7 & 68.2 & & 1,910 \\
\hline & 31BTU28 & 0.32 & 3.1 & 129.7 & 0.55 & -2.6 & 60.9 & & 4,500 \\
\hline & 31BTU17 & 0.30 & -7.0 & 121.0 & 0.52 & -0.3 & 59.9 & & 15,780 \\
\hline & 31BTU33 & 0.24 & -5.8 & 101.5 & 0.42 & -1.1 & 51.7 & & 27,020 \\
\hline & 31BTU15 & 0.20 & -7.3 & 89.6 & 0.35 & -1.3 & 40.1 & & 108,800 \\
\hline & 31BTU21 & 0.17 & -8.0 & 74.0 & 0.29 & -0.8 & 44.2 & & $>1,012,520$ \\
\hline \multirow{2}{*}{$\begin{array}{l}\text { Load } \\
\text { path }\end{array}$} & Specimen & $\Delta \varepsilon / 2$ & $\sigma_{\mathrm{m}}$ & $\Delta \sigma / 2$ & $\Delta \gamma / 2$ & $\tau_{\mathrm{m}}$ & $\Delta \tau / 2$ & $\varepsilon_{\mathrm{m}}$ & $N_{\mathrm{f}}$ \\
\hline & ID & $(\%)$ & $(\mathrm{MPa})$ & $(\mathrm{MPa})$ & $(\%)$ & (MPa) & $(\mathrm{MPa})$ & $(\%)$ & (cycles) \\
\hline \multirow{2}{*}{ V } & 31BTU64 & 0.5 & 22.0 & 166.6 & 0.87 & -4.3 & 84.3 & 0.5 & 582 \\
\hline & 31BTU65 & 0.5 & 6.5 & 149.6 & 0.87 & 4.4 & 81.2 & -0.5 & 659 \\
\hline \multirow{2}{*}{$\begin{array}{c}\text { Load } \\
\text { path }\end{array}$} & Specimen & $\Delta \varepsilon / 2$ & $\sigma_{\mathrm{m}}$ & $\Delta \sigma / 2$ & $\Delta \gamma / 2$ & $\tau_{\mathrm{m}}$ & $\Delta \tau / 2$ & $\alpha$ & $N_{\mathrm{f}}$ \\
\hline & ID & $(\%)$ & $(\mathrm{MPa})$ & (MPa) & $(\%)$ & (MPa) & (MPa) & $\left(^{\circ}\right)$ & (cycles) \\
\hline \multirow{5}{*}{ VI } & 31BTU71 & 0.29 & -2.9 & 79.9 & 1.2 & -0.3 & 62.2 & -22.5 & 960 \\
\hline & 31BTU74 & 0.70 & 15.2 & 172.5 & 0.5 & -2.1 & 37.5 & -67.5 & 684 \\
\hline & 31BTU75 & 0.53 & 4.6 & 140.6 & 0.92 & -2.2 & 64.7 & -45 & 974 \\
\hline & 31BTU77 & 0.29 & 8.5 & 93.3 & 1.2 & 4.8 & 85.8 & 22.5 & 392 \\
\hline & 31BTU80 & 0.69 & 39.0 & 199.6 & 0.5 & 3.7 & 38.1 & 67.5 & 560 \\
\hline \multirow{2}{*}{$\begin{array}{c}\text { Load } \\
\text { path }\end{array}$} & Specimen & & $\Delta \gamma / 2$ & & $\sigma_{\text {stat }}$ & $\tau_{\mathrm{m}}$ & $\Delta \tau / 2$ & & $N_{\mathrm{f}}$ \\
\hline & ID & & $(\%)$ & & (MPa) & (MPa) & (MPa) & & (cycles) \\
\hline & 31BTU38 & & 0.52 & & 150 & -1.3 & 61.7 & & 10,507 \\
\hline \multirow[t]{5}{*}{ VII } & 31BTU35 & & 0.52 & & 100 & -0.9 & 59.3 & & 17,949 \\
\hline & 31BTU37 & & 0.52 & & 50 & 0.5 & 60.8 & & 33,707 \\
\hline & 31BTU49 & & 0.52 & & -50 & 1.5 & 58.7 & & 25,533 \\
\hline & 31BTU51 & & 0.52 & & -75 & 1.0 & 62.7 & & 80,206 \\
\hline & $31 \mathrm{BTU} 36$ & & 0.52 & & -100 & 1.2 & 61.5 & & 39,587 \\
\hline
\end{tabular}

$\Delta \varepsilon / 2=$ axial strain amplitude; $\sigma_{\mathrm{m}}=$ mean axial stress; $\Delta \sigma / 2=$ axial stress amplitude; $\Delta \gamma / 2=$ shear strain amplitude; $\tau_{\mathrm{m}}=$ mean shear stress; $\Delta \tau / 2=$ shear stress amplitude; $N_{\mathrm{f}}=$ number of cycles to failure; $\varepsilon_{\mathrm{m}}=$ mean axial strain; $\sigma_{\mathrm{stat}}=$ static axial stress. 


\section{Multiaxial fatigue criteria}

A large number of fatigue criteria have been proposed over the years to predict the fatigue life under multiaxial loading conditions [22-28]. The fatigue criteria based on the material critical plane are now widely accepted for multiaxial fatigue damage evaluation. The appeal of this approach is that it inherently incorporates the directional nature of the fatigue damage process, i.e., the observation that cracks grow on specific material planes of maximum fatigue damage. Furthermore, satisfactory fatigue life predictions have been reported for a number of engineering materials under a variety of loading conditions [22,28-34].

Three critical plane fatigue criteria will be evaluated based on the observed fatigue behavior of the extruded AZ31B Mg alloy: the multiaxial version of the SWT criterion [22], the Fatemi-Socie criterion [19], and the Jiang criterion [20]. The SWT criterion has a simple form without containing a material constant. It is suited for multiaxial fatigue of aluminum alloys [30,32] and stainless steels $[22,24,33]$ which display normal cracking behavior. The Fatemi-Socie model is designed for materials exhibiting shear cracking behavior. The Jiang criterion is based on an energy concept that considers different cracking behavior of materials. A brief description of the three criteria is given below.

\subsection{Smith-Watson-Topper criterion}

The Smith, Watson, and Topper (SWT) criterion [35] was originally developed to consider the mean stress effect under uniaxial loading. Socie [22] proposed a multiaxial version of the SWT criterion based on the critical plane concept for materials that exhibit normal cracking behavior. The SWT criterion can be expressed as,

$$
\mathrm{FP}=\frac{\Delta \varepsilon}{2}\left\langle\sigma_{\mathrm{nmax}}\right\rangle
$$

where FP denotes "fatigue parameter," $\Delta \varepsilon / 2$ is the normal strain amplitude, and $\sigma_{\mathrm{nmax}}$ is the maximum normal stress in a loading cycle. Both $\Delta \varepsilon / 2$ and $\sigma_{\mathrm{nmax}}$ are on the maximum normal material plane. The symbols \langle\rangle represent the MacCauley brackets defined as $\langle x\rangle=0.5(x+|x|)$. The MacCauley brackets are used to ensure that no negative damage is produced. The critical plane can be defined as the plane that experiences the maximum normal strain amplitude, and the maximum normal stress is evaluated on the critical plane. In the current work, the critical plane is defined as the plane where the fatigue parameter expressed by Eq. (1) is a maximum. Arguments can be made with regard to the reasonableness of the choice [20,31]. It is worth mentioning that fatigue life predictions are not practically influenced by the definition of the critical plane. 


\subsection{Fatemi-Socie criterion}

Fatemi and Socie [19] developed a multiaxial fatigue criterion based on a fatigue parameter expressed as,

$$
\mathrm{FP}=\frac{\Delta \gamma}{2}\left(1+K \frac{\sigma_{\mathrm{n} \max }}{\sigma_{\mathrm{y}}}\right)
$$

where $\Delta \gamma / 2$ is the shear strain amplitude and $\sigma_{\mathrm{nmax}}$ is the maximum normal stress in a loading cycle on the critical material plane. $\sigma_{\mathrm{y}}$ is the yield strength of the material and $K$ is a material constant. The Fatemi-Socie criterion was designed for materials and loading conditions that result in failure due to shear cracking. As with the multiaxial SWT criterion described in the previous section, the critical plane for the Fatemi-Socie criterion is defined in the current work as the plane where the fatigue parameter defined in Eq. (2) is a maximum.

\subsection{Jiang criterion}

The fatigue criterion developed by Jiang [18] is based on the postulate that plastic strain energy is the major cause of fatigue damage. The criterion takes the following incremental form,

$$
\mathrm{d} D=\left(\frac{\sigma_{\mathrm{mr}}}{\sigma_{0}}-1\right\rangle^{m}\left(1+\frac{\sigma}{\sigma_{\mathrm{f}}}\right) \mathrm{d} Y
$$

where

$$
\mathrm{d} Y=b \sigma \mathrm{d} \varepsilon^{\mathrm{p}}+\frac{1-b}{2} \tau \mathrm{d} \gamma^{\mathrm{p}}
$$

In the above expressions, $D$ represents the fatigue damage, $Y$ is the plastic strain energy density on a material plane, and the prefix $d$ denotes an increment. $\sigma$ is the normal stress and $\tau$ is the shear stress on a material plane, and $\varepsilon^{\mathrm{p}}$ and $\gamma^{\mathrm{p}}$ represent plastic strains corresponding to $\sigma$ and $\tau$, respectively. $\sigma_{\mathrm{mr}}$ is a material memory stress. $\sigma_{0}$ and $\sigma_{\mathrm{f}}$ are the endurance limit and the true fracture stress of the material, respectively. The symbols $b$ and $m$ are material constants. The MacCauley brackets \langle\rangle are used to ensure that when $\sigma_{\mathrm{mr}} \leq \sigma_{0}$ the fatigue damage is minimal. The critical plane is defined as the material plane where the fatigue damage accumulation first reaches a critical value, $D_{0}$.

For constant amplitude loading, the stabilized stress-strain responses can be used to evaluate the fatigue damage accumulated over a loading cycle. In this setting, the Jiang criterion can be simplified to

$$
\Delta D N_{\mathrm{f}}=D_{0}
$$

where 


$$
\Delta D=\left\langle\frac{\sigma_{\mathrm{mr}}}{\sigma_{0}}-1\right\rangle^{m} \oint\left(1+\frac{\sigma}{\sigma_{\mathrm{f}}}\right)\left(b \sigma \mathrm{d} \varepsilon^{\mathrm{p}}+\frac{1-b}{2} \tau \mathrm{d} \gamma^{\mathrm{p}}\right)
$$

In the above expressions, $\Delta D$ is the fatigue damage per loading cycle, $N_{\mathrm{f}}$ in Eq. (5) is the number of cycles to failure, $\sigma_{\mathrm{mr}}$ in Eq. (6) is the maximum von Mises equivalent stress in the stabilized stress history, and the integration is taken over a loading cycle.

The Jiang criterion has a number of appealing features. Being a critical plane criterion, it incorporates the directional nature of the fatigue damage phenomenon. Due to the incremental form of the criterion, it can deal with general loading without the need of a cycle counting method. The fatigue criterion makes use of a material memory parameter to capture the effects of loading sequence and variable amplitude loading on fatigue life. The mean stress effect is accounted for by the second term on the right side of Eq. (3). Different fatigue cracking behavior can be represented with the help of the parameter $b$ in Eq. (4). The value of $b$ ranges from 0.0 to 1.0. By selecting $b \leq 0.375$, shear cracking can be described. When $b \geq 0.5$, the criterion mimics tensile cracking behavior. Mixed cracking behavior is represented when $0.375<b<0.5$ [20]. The dependence of the fatigue cracking behavior on the loading amplitude, or fatigue life, can also be incorporated into the criterion by relating the constant $b$ to the memory parameter or an equivalent stress amplitude. A detailed presentation of the fatigue criterion, including the procedure to determine the material constants, can be found in Ref. [20].

\section{Results and discussion}

The strain-life fatigue experimental results and the cracking behavior of the extruded AZ31B $\mathrm{Mg}$ alloy under fully reversed tension-compression are shown in Fig. 3. A horizontal arrow denotes a run-out fatigue experiment. Two three-parameter curves were found to best describe the experimental data. The kink point at $\Delta \varepsilon / 2=0.45 \%$ is associated with a change of the salient deformation mechanism: twinning-detwinning activity dominates cyclic plastic deformation for strain amplitudes above the kink point and dislocation slips are pronounced for strain amplitudes below the kink point $[11,15]$. For the tension-compression experiments, the angle of penetration of the fatigue crack in the depth direction was determined by observing the region where fatigue crack initiation occurred. A fatigue cracking surface perpendicular to the loading direction was consistently observed for the strain amplitudes investigated. Such cracking behavior is shown in Fig. 4 for Specimen 31BTU81. It is noticed that the crack observations found in the present work

are consistent with the ones by Xiong et al. [11] in AZ31B dog-bone plate specimens subjected to strain-controlled tension-compression at different strain ratios. 


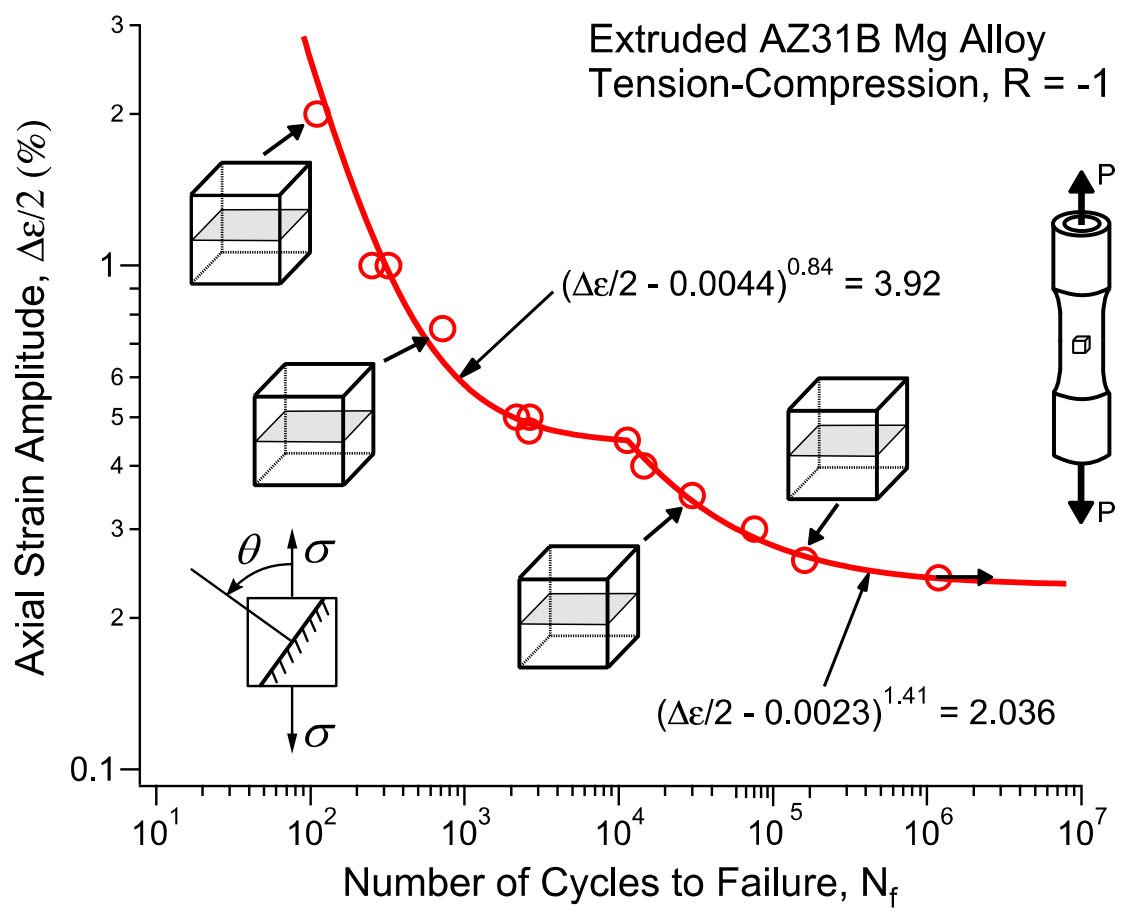

Figure 3. Strain-life curve and cracking behavior under fully reversed strain-controlled tensioncompression.

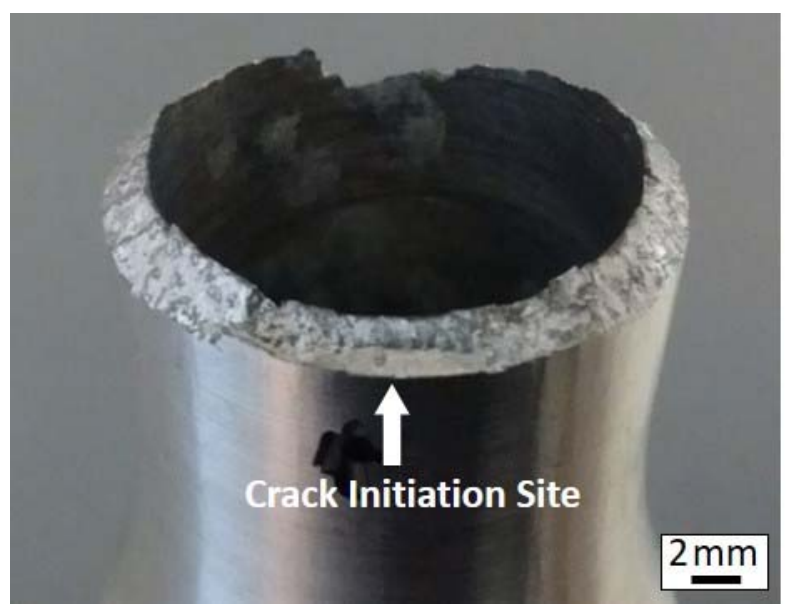

Figure 4. Photograph of the fracture surface of Specimen 31BTU81 showing a fatigue cracking surface perpendicular to the specimen axis. 


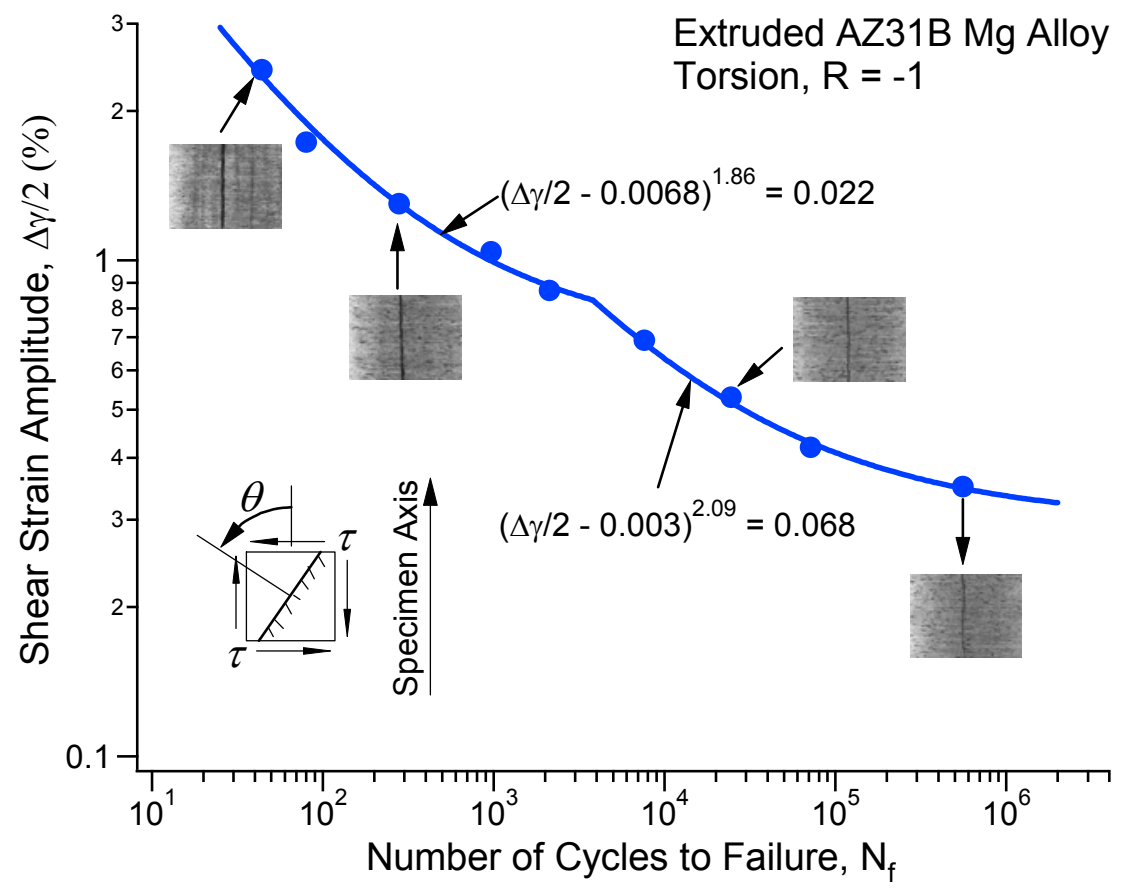

Figure 5. Strain-life curve and cracking behavior under fully reversed strain-controlled torsion.

The strain-life fatigue data and the cracking behavior of the extruded AZ31B Mg alloy under fully reversed torsion are shown in Fig. 5. Two three-parameter curves were used to describe the strain-life curve. Similar to tension-compression, a kink point can be identified in the strain-life curve. A prevalence of twinning-detwinning activity can be observed at high strain amplitudes, whereas dislocation slips are pronounced at low strain amplitudes [15]. Typical cracking observed in pure torsion is enclosed in Fig. 5. A shear crack along the specimen axis was consistently observed for the all the shear strain amplitudes conducted.

According to the categorization of the cracking behavior described by Jiang [20], the extruded AZ31B Mg alloy exhibits mixed cracking over the investigated range of fatigue lives. A material exhibits mixed cracking behavior if early fatigue cracking is observed on the maximum normal plane for tension-compression loading but on the maximum shear plane for torsion loading. It is noticed that the mixed cracking behavior of the AZ31B Mg alloy observed in the current study is consistent with the cracking orientations under tension-compression and torsion observed by Albinmousa and Jahed [17] on a Mg alloy with an identical designation. It should be pointed out that the aforementioned observation was made on cracking behavior of tension-compression and torsion fatigue experiments of AZ31B Mg alloy when the strain amplitude was lower than $2 \%$ for tension-compression and $2.5 \%$ for pure torsion. Recent studies revealed that the normal of the cracking plane was approximately 45 degrees from the loading axis under tension-compression for ZK60 Mg alloys when the strain amplitude was large than 3.0\% under tension-compression with the corresponding fatigue life being less than 100 loading cycles [36,37]. It is possible that a similar phenomenon exists when the extruded AZ31B Mg alloy is subjected to a strain amplitude larger than $3 \%$. 
Figure 6 is a plot of the SWT parameter versus fatigue life for the tension-compression and torsion tests. Clearly, the SWT parameter is not capable of correlating the two basic experiments. Albinmousa and Jahed [19] reported a similar observation on AZ31B thin-walled tubes. Due to the inability of the SWT parameter to correlate the tension-compression and torsion fatigue experiments, its further evaluation using multiaxial loading paths (Paths III-VII) will not be considered. However, it should be noticed that the SWT parameter is capable of modeling the mean stress effect of extruded AZ61A [9] and extruded AZ31B [11] Mg alloys under tensioncompression loading at different strain ratios [11].

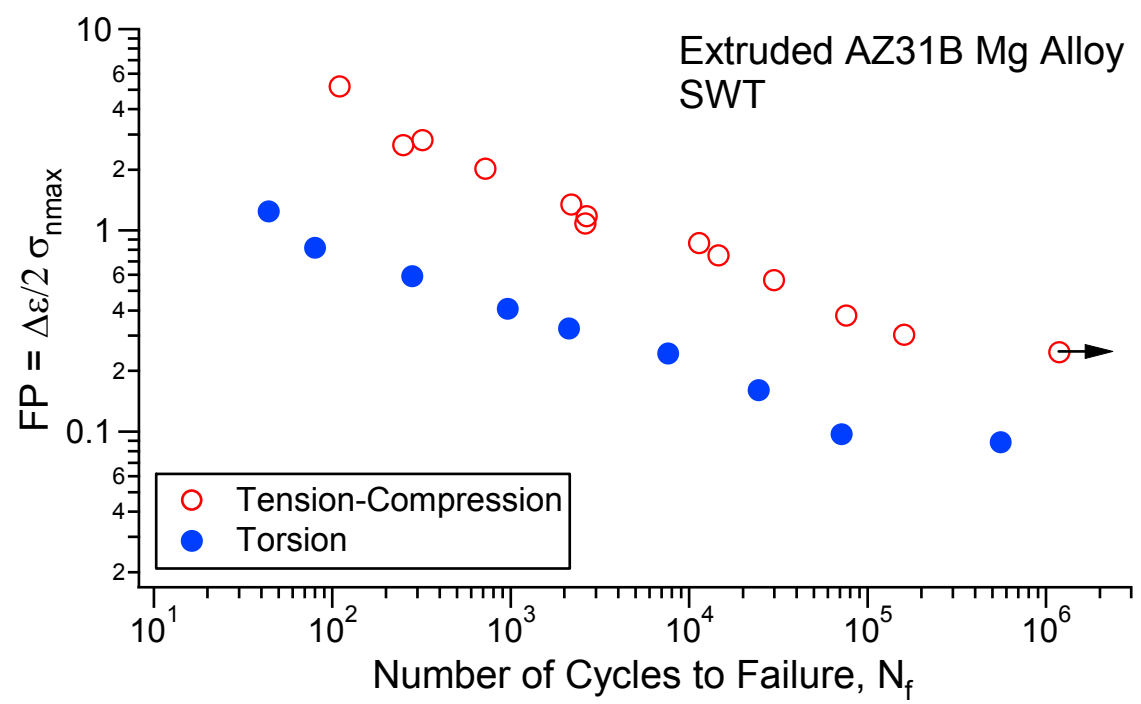

Figure 6. SWT parameter versus fatigue life for the tension-compression and torsion tests.

The correlation of the test data with the Fatemi-Socie parameter was carried out with the following three-parameter relationship:

$$
\left\langle\mathrm{FP}-\mathrm{FP}_{0}\right\rangle^{\xi} N_{\mathrm{f}}=C
$$

where FP is the Fatemi-Socie fatigue parameter as being defined by Eq. (2) and $\mathrm{FP}_{0}, \xi$, and $C$ are material constants. The MacCauley brackets \langle\rangle are used to ensure that when the fatigue parameter $\mathrm{FP}$ is less than the threshold value $\mathrm{FP}_{0}$, fatigue damage is minimal. The material constants used in the Fatemi-Socie criterion were determined by fitting Eq. (7) to the tension-compression and torsion test data, and they are listed in Table 3. The solid line in Fig. 7 represents the adjusted FP$N_{\mathrm{f}}$ curve. The dotted lines mark factor-of-two boundaries in fatigue life. Results shown in Fig. 7 suggest that the Fatemi-Socie model can bring together the fully reversed tension-compression and torsion fatigue data properly for the material under investigation. 
Table 3. Material constants used in the fatigue criteria.

\begin{tabular}{ll}
\hline Fatemi-Socie criterion & Jiang criterion \\
\hline$K=0.17$ & $b=0.38$ \\
$\sigma_{\mathrm{y}}=244 \mathrm{MPa}$ & $\sigma_{0}=71 \mathrm{MPa}$ \\
$\mathrm{FP}_{0}=0.00285$ & $m=0.9$ \\
$\xi=2.5$ & $\sigma_{\mathrm{f}}=338 \mathrm{MPa}$ \\
$C=0.0048$ & $D_{0}=4 \times 10^{8} \mathrm{Nm} / \mathrm{m}^{3}$ \\
\hline
\end{tabular}

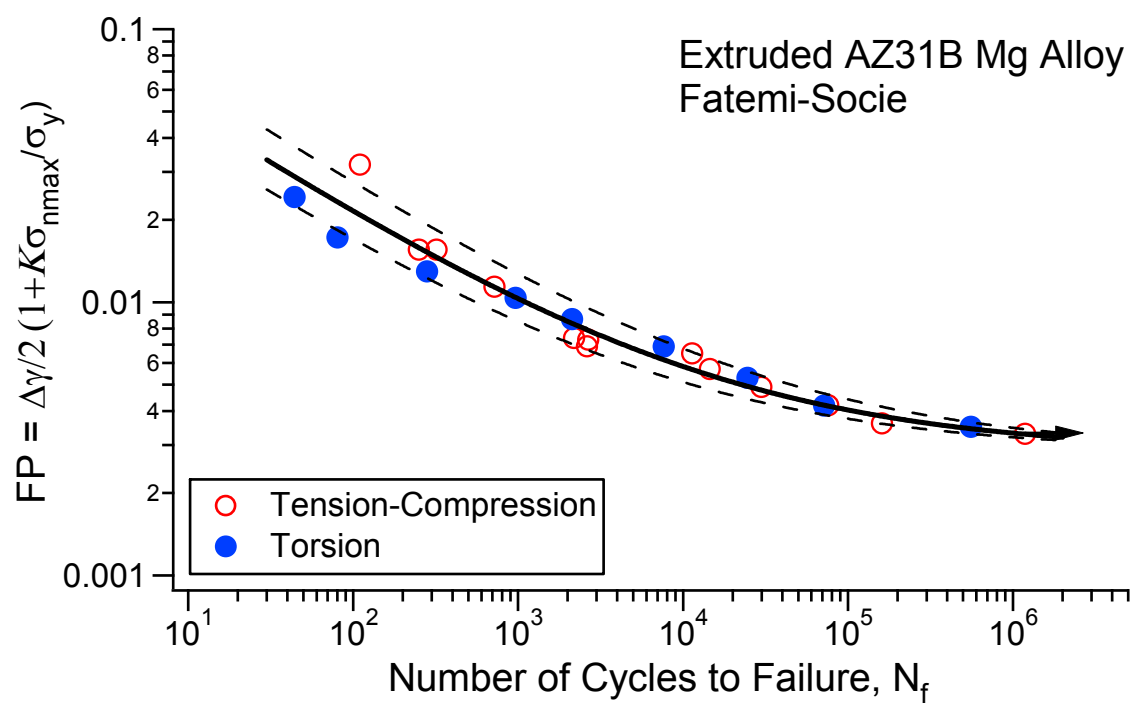

Figure 7. Fatemi-Socie criterion for fully reversed tension-compression and torsion.

The material constants of the Jiang criterion can be determined by adjusting the $\Delta D-N_{\mathrm{f}}$ relationship (Eq. 5) so as to line up the tension-compression and torsion test data. In this procedure, it is important to select a material constant $b$ that properly reflects the cracking behavior of the material under tension-compression and torsion. As previously discussed, the extruded AZ31B Mg alloy exhibited mixed cracking behavior over the investigated range of fatigue lives. To reflect this behavior, the material constant $b$ must have a value between 0.375 and 0.5 . Hence, the material constants were determined by fitting Eq. (5) to the tension-compression and torsion test data with the restriction that $0.375 \leq b \leq 0.5$. The material constants for the Jiang criterion are listed in Table 3 . Figure 8 shows the adjusted $\Delta D-N_{\mathrm{f}}$ relationship (solid line) together with the factor-of-two boundaries in fatigue live (dotted lines). Most of the test data are within the factorof-two boundaries, signifying a reasonable correlation. 


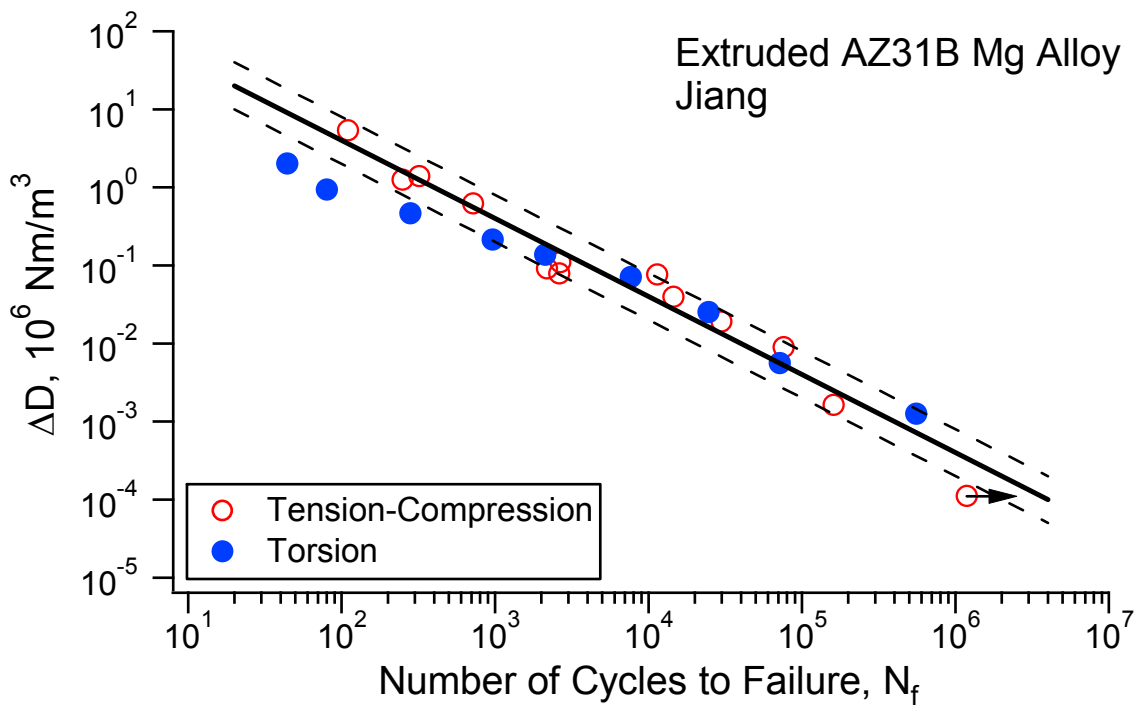

Figure 8. Determination of the material constants in Jiang criterion with the tension-compression and torsion data.

The observed fatigue lives and the predictions made with the Fatemi-Socie and Jiang criteria are compared in Figs. 9 and 10, respectively. The solid diagonal lines in these figures represent a perfect match between predicted and observed fatigue lives, and the two dashed lines define the factor-of-two boundaries. To compute the fatigue live of a given test, the stabilized stress-strain history obtained at approximately half the fatigue life was used as input in both criteria. The Fatemi-Socie criterion provides good fatigue life predictions, with only a few data points falling outside the factor-of-two boundaries. Most of the fatigue life predictions based on the Jiang criterion are within the factor-of-two boundaries, indicating a reasonable correlation between the model and experiment. The main differences between the fatigue life predictions based on the Fatemi-Socie and Jiang criteria occur for a few torsion and $90^{\circ}$ out-of-phase tests. For these cases, the accuracy of the Fatemi-Socie criterion is better. 


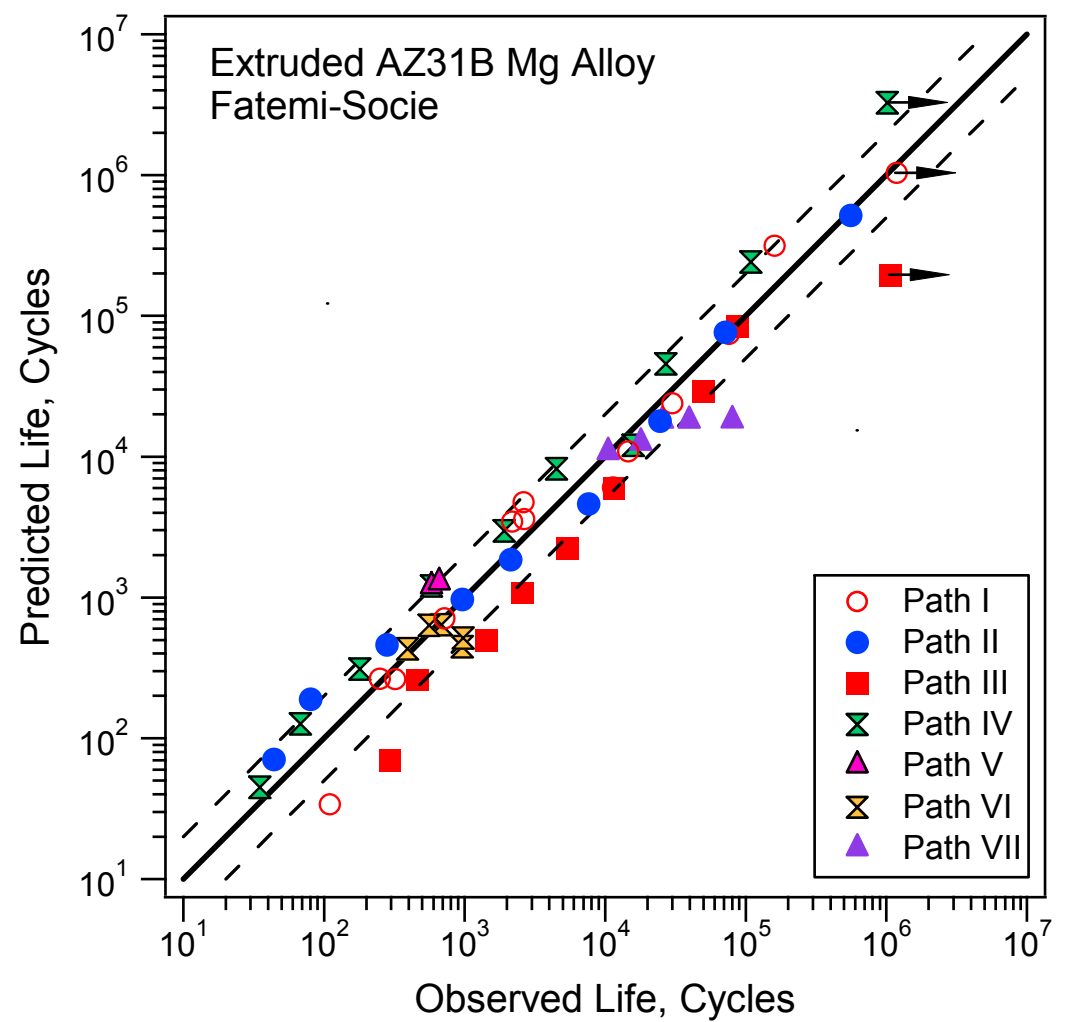

Figure 9. Observed versus predicted fatigue lives by Fatemi-Socie criterion.

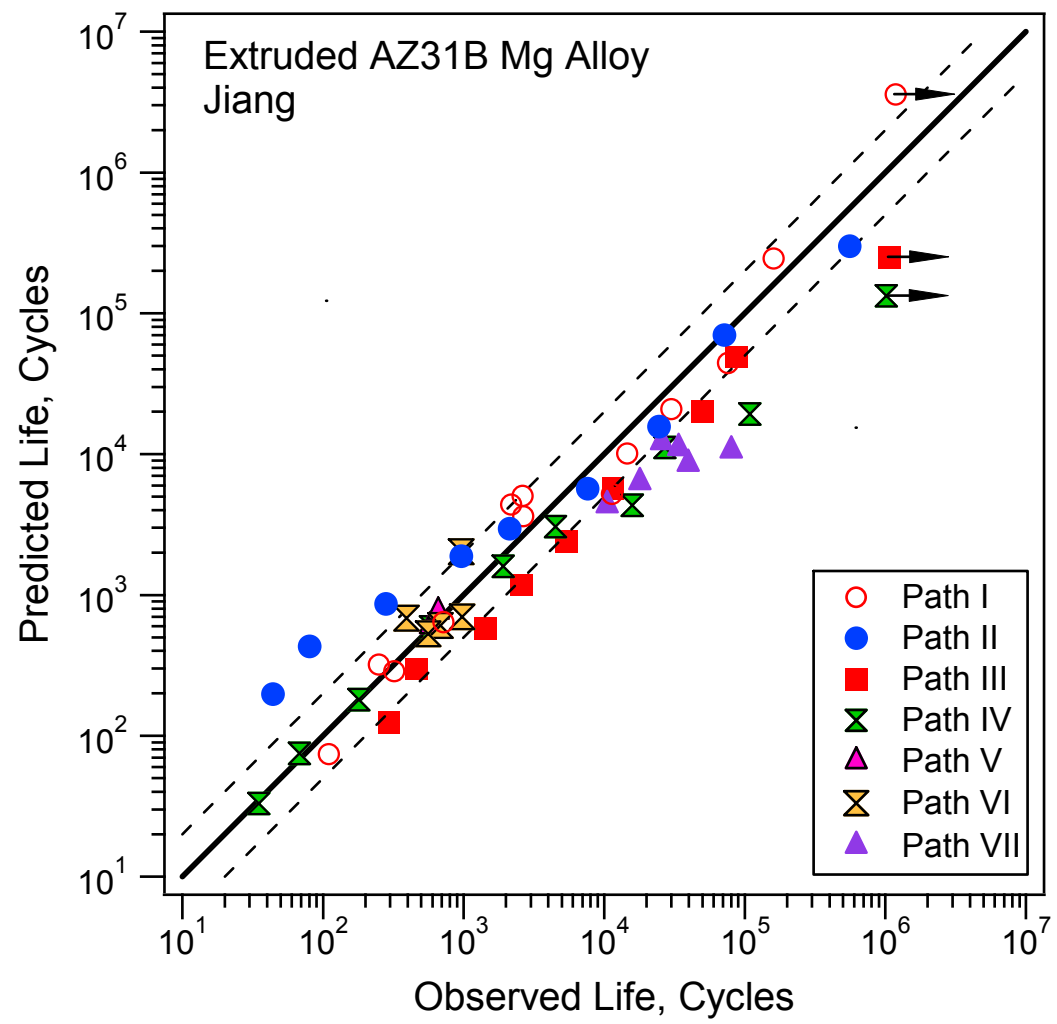

Figure 10. Observed versus predicted fatigue lives by Jiang criterion. 
A critical plane approach is based on the notion that cracks initiate on planes of maximum fatigue damage in the material. Therefore, a critical plane fatigue criterion should be regarded as successful if it can satisfactorily predict both the fatigue life and the critical plane orientation for different loading conditions. For a tubular specimen, the orientation of the surface crack can be defined by the angle $\theta$ shown in Fig. 11 since most combined axial-torsion loading resulted in a crack surface perpendicular to the specimen surface. When $\theta=0^{\circ}$ the cracking plane is perpendicular to the specimen axis. The crack initiation site and the early cracking orientation were identified by examining the surface cracks after the termination of an experiment. The angle $\theta$ was measured from the specimen axis to the normal of the cracking surface. In addition to the dominant crack that grew into a large crack, secondary cracks were also observed in some specimens, notably the ones subjected to proportional loading (Path III). Both types of crack are shown in Fig. 12 for Specimen 31BT30.

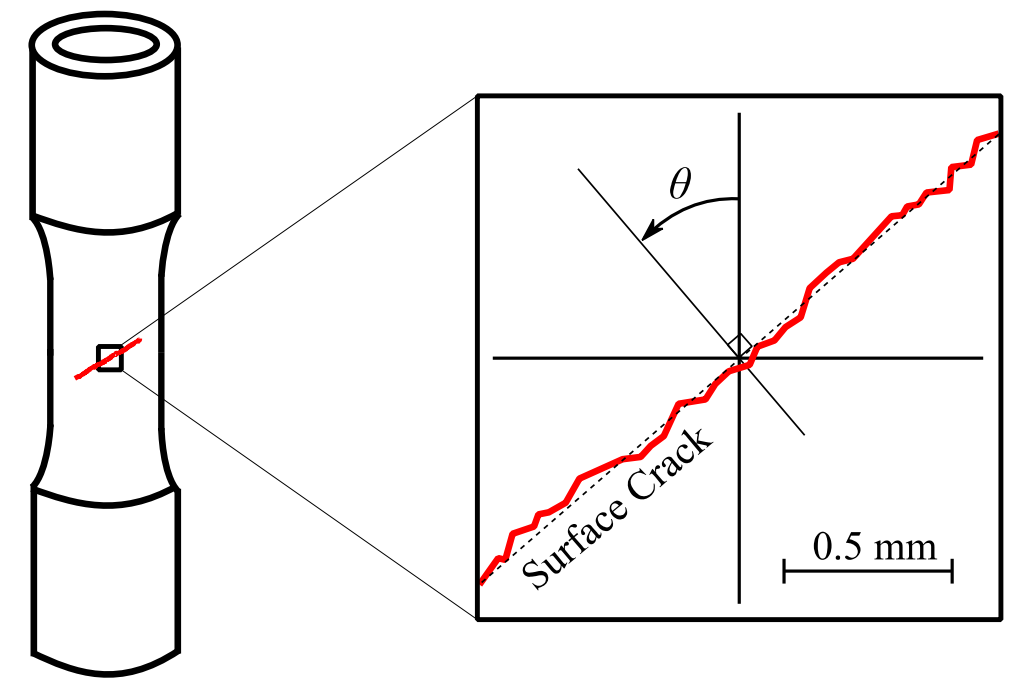

Figure 11. Definition of the surface cracking orientation for the tubular specimen.

a

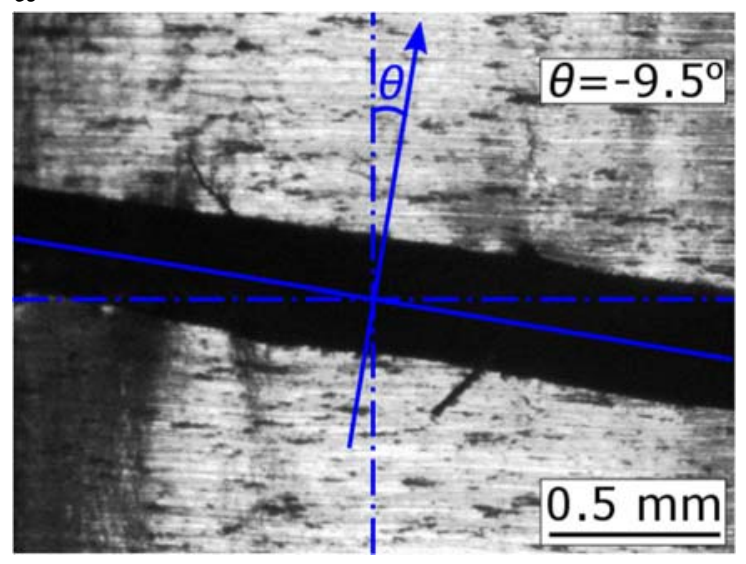

b

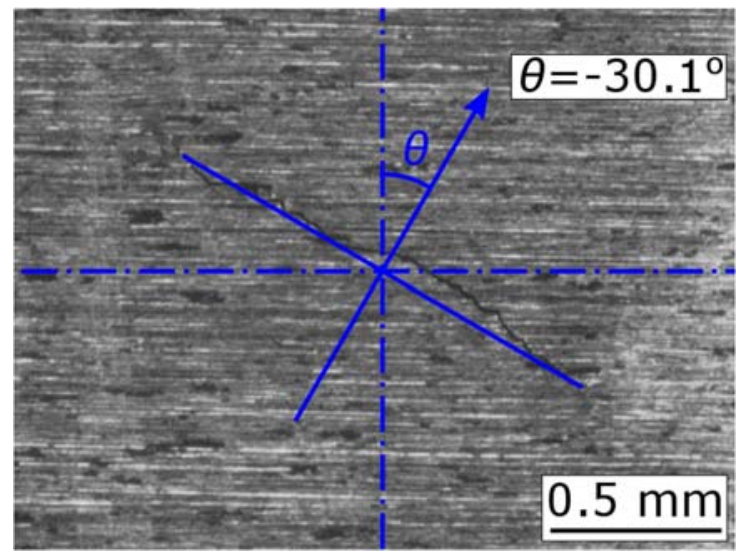

Figure 12. Optical microscopy observation of the dominant crack (a) and of a secondary crack (b) in Specimen 31BTU30. 
For a given loading condition, several material planes may experience identical or very similar fatigue damage according to a particular fatigue criterion. Furthermore, inhomogeneity in the material on these severely damaged planes may favor crack initiation in an orientation not exactly coincident with that of maximum fatigue damage. Therefore, to discuss the performance of a fatigue criterion in predicting the critical plane orientation, it is reasonable to define a range of potential critical planes. In the current investigation, a range of $10 \%$ from the maximum fatigue damage is used for the discussion of possible cracking material planes predicted by a fatigue criterion. The choice of a range of $10 \%$ from the maximum fatigue damage was not based on any physical consideration. It should be regarded as an engineering criterion to select the range of material planes that may experience similar fatigue damage according to a given multiaxial fatigue model. The fatigue damage per loading cycle is the reciprocal of the predicted fatigue life under constant amplitude loading.

The comparisons between the observed crack angles and the predictions of the Fatemi-Socie and Jiang criteria are shown in Figs. 13 and 14, respectively. The solid circles in these figures indicate the angles of the observed dominant crack, while the by solid squares represent the orientations of the secondary cracks. The range bars are the predicted ranges of the cracking directions by the models. The results show that the Jiang criterion outperforms the Fatemi-Socie criterion in predicting the critical plane orientations. Among the 55 observed crack angles, the Fatemi-Socie criterion provided 36\% correct predictions, whereas most of the crack angles (78\%) predicted by the Jiang criterion were correct. The undesirable performance of the Fatemi-Socie criterion for cracking orientation predictions is not surprising because the model was developed for shear cracking fatigue failure, whereas the extruded AZ31B exhibits mixed cracking. Comparing the observed and predicted crack orientations under tension-compression (Path I) and torsion (Path II) in Fig. 13, it can be found that the shear cracks $\left(\theta=90^{\circ}\right)$ exhibited by the extruded AZ31B under torsion were correctly predicted by the Fatemi-Socie criterion. However, the material displayed tensile cracking $\left(\theta=0^{\circ}\right)$ under tension-compression, whereas the FatemiSocie criterion predicted shear cracking around the $\theta= \pm 45^{\circ}$ planes.

The good performance of the Jiang criterion in predicting the cracking orientations can be attributed to its capacity to predict mixed cracking behavior and to the wider range of critical planes predicted by the criterion. Further investigations are needed to confirm whether or not a wide range of material planes experience similar fatigue damage. In an earlier study [31], discussions were made with regard to the "narrow" and "wide" predicted angles. This remains a question waiting for an answer. 


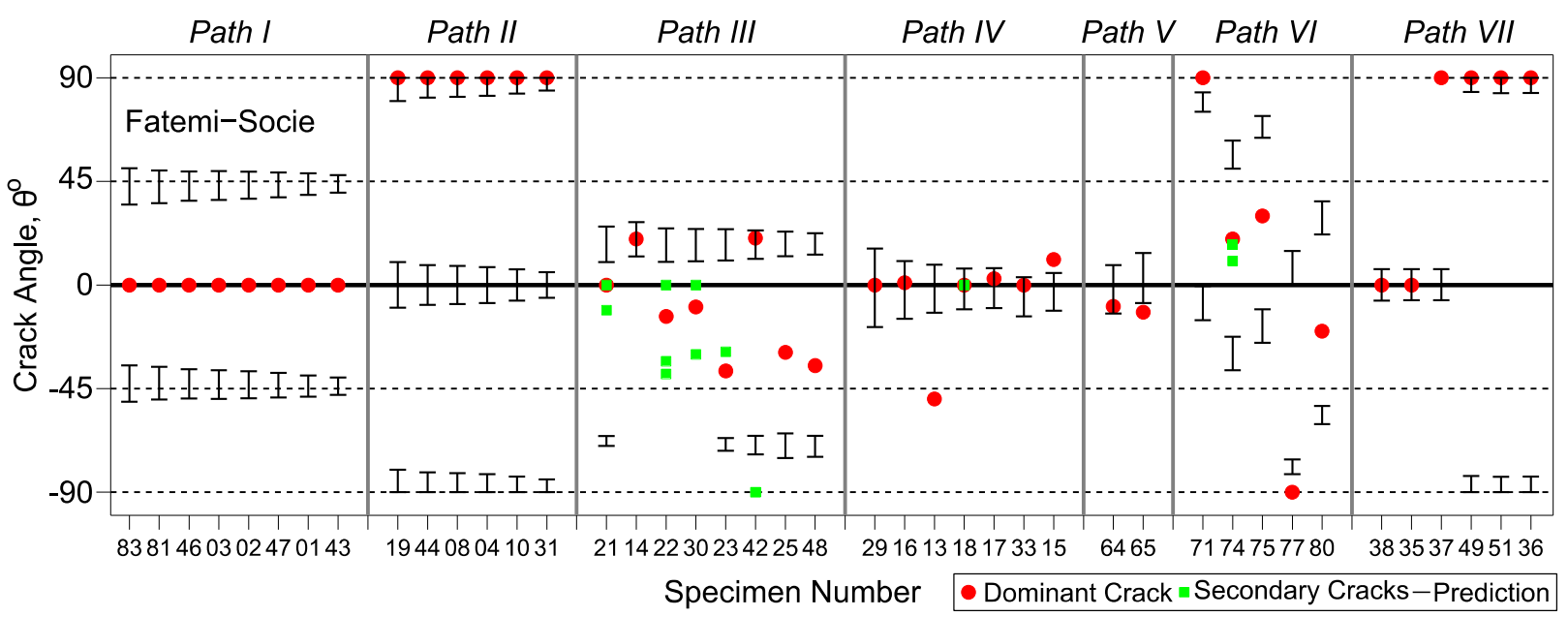

Figure 13. Observed crack angles and predictions of the Fatemi-Socie criterion.

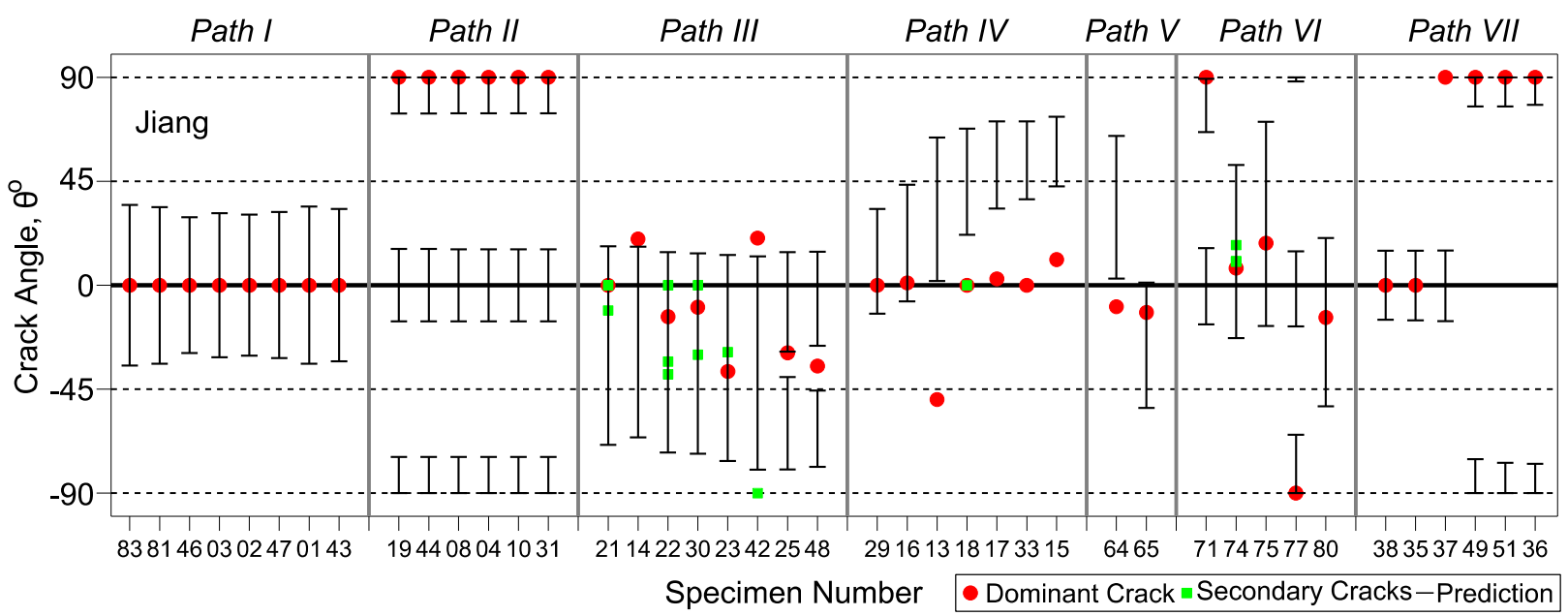

Figure 14. Observed crack angles and predictions of the Jiang criterion.

Both the Fatemi-Socie and the Jiang criteria provided reasonable fatigue life and cracking orientation predictions for the AZ31B Mg alloy. The overall accuracy of the fatigue life predictions of the Fatemi-Socie criterion was better than that of the Jiang criterion. In particular, it is noticed that the fatigue life predictions of the Jiang criterion for the pure torsion and $90^{\circ}$ outof-phase experiments are not as satisfactory as the ones obtained for conventional metallic materials tested under similar conditions [31,33,34]. On the other hand, the Jiang criterion outperformed the Fatemi-Socie criterion with respect to the cracking orientation predictions, the only exception being the $90^{\circ}$ out-of-phase (Path IV) experiments. In $\mathrm{Mg}$ and $\mathrm{Mg}$ alloys, twinningdetwinning deformation mechanisms can be activated depending on the amplitude, loading type, and loading path. Twinning-detwinning and dislocation slips may interact and such an interaction may have contributed to the unsatisfactory performance of a fatigue model that was developed for considering one major fatigue mechanism. Further studies should be carried out to determine whether or not an existing critical plane model can serve as a base for a fatigue model that is suitable for Mg alloys. 


\section{Further discussion}

Xiong et al. [15] evaluated the Jiang criterion based on AZ31B Mg alloy test data. Using $b=$ 0 , quite reasonable life predictions were found. However, the cracking behavior observed in the tension-compression tests was not correctly predicted with $b=0$. This is because when $b=0$ the Jiang fatigue criterion predicts shear cracking. In the current study, the Jiang fatigue criterion was evaluated using $b=0.38$ because the material was found to exhibit mixed cracking. With $b=$ 0.38, the fatigue life predictions for Paths I-IV were similar to the ones obtained by Xiong et al. [15] due to the insensitivity of the fatigue life prediction using the Jiang criterion to the selection of $b$. Furthermore, reasonable fatigue life predictions were also obtained for the additional loading paths (Paths V-VII) evaluated in this study. With respect to the description of the cracking behavior, a significant improvement was obtained by using $b=0.38$ instead of $b=0$. Indeed, the cracking behavior under tension-compression and torsion was appropriately described, and most of the crack orientations observed in the multiaxial tests were correctly predicted.

The cracking behavior discussed in the current work is based on an observation of the early cracking orientation at the millimeter scale. This is because the critical plane models under consideration take as input macroscopic stresses and strains. As the macroscopic stress and strain at a material point represent averages of the stress and strain fields acting on the aggregate of grains, it is appropriate to interpret the cracking orientation predicted by a macroscopic critical plane criterion as the average (or overall) orientation of a fatigue crack. It is also noticed that the fatigue crack path in metallic materials is generally irregular at the microscopic level permitting different interpretations of cracking orientations. The local orientations of the crack path can be very different from the overall macroscopic crack orientation. It is impractical to correlate or interpret the microscopic crack of a polycrystalline engineering material by using a critical plane fatigue criterion designed for an idealized continuum. In order to carry out a detailed analysis of the microscopic fatigue crack path, crystallographic critical plane criteria have to be invoked. McDowell and co-workers $[38,39]$ have tried to describe small crack growth in a few grains by means of crystallographic versions of the Fatemi-Socie criterion. However, the work by McDowell is exploratory in nature because the determination of real stresses and strains within a grain and particularly at the grain boundary is still a very difficult task.

An insight into the difference between the cracking behavior predictions by the Fatemi-Socie and Jiang criteria can be provided by examining the case of Specimen 31BTU22 (refer to Table 2). Figure 15 shows the observed cracking orientations and the predicted fatigue damage distributions over the material plane orientation. The damage distributions of the two criteria are remarkably different. For the case under examination, it can be argued that the damage distribution predicted by the Jiang criterion provides a more reasonable description of the observed cracking behavior. This is because the dominant crack and the three secondary cracks were observed among the most severely damaged planes according to the Jiang criterion. In contrast, minimal damage

was predicted by the Fatemi-Socie criterion on the observed cracking planes. Furthermore, the 
variety of the observed cracking orientations (with angles within the range $-38.6^{\circ}-0^{\circ}$ ) can be justified by looking at the wide range of critically damaged planes predicted by the Jiang criterion.

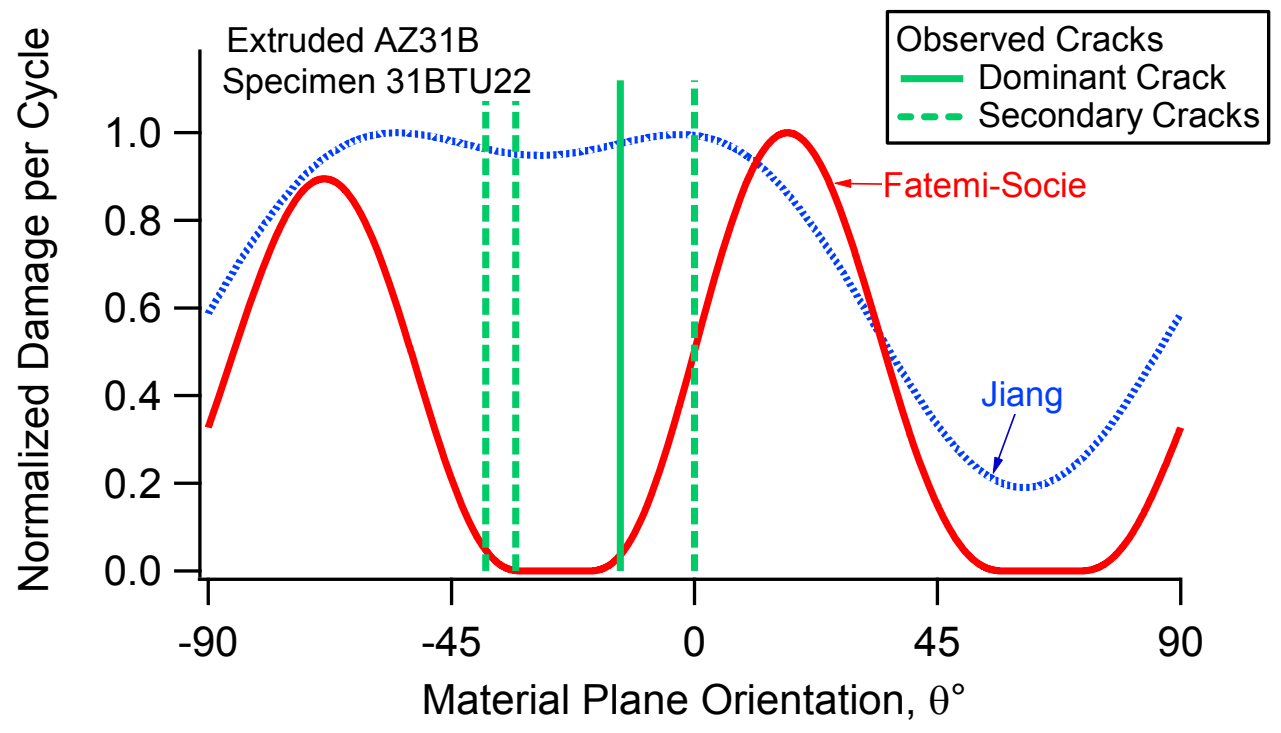

Figure 15. Observed cracking orientations for Specimen 31BTU22 and fatigue damage distributions predicted by the Fatemi-Socie and Jiang criteria.

Two major differences exist between the conventional metallic materials and the wrought $\mathrm{Mg}$ alloys: deformation mechanisms and anisotropy. Plastic deformation of the conventional materials is mainly due to dislocation slips while for $\mathrm{Mg}$ alloys twinning-detwinning is a dominant mechanism when the strain amplitude is large under cyclic loading. Fatigue damage due to different deformation mechanisms might be different and a fatigue model may need to consider such a difference. Material anisotropy is the other major feature of Mg alloys. $\mathrm{Mg}$ and $\mathrm{Mg}$ alloys have a hexagonal close-packed structure and wrought $\mathrm{Mg}$ alloys typically have a strong initial texture. The cyclic plastic deformation along the $c$-axis is dramatically different from that when the load is applied along a direction perpendicular to the $c$-axis for a wrought $\mathrm{Mg}$ alloy with a strong basal texture [40,41]. Fatigue properties of the wrought Mg alloys are dependent on the orientation of the testing specimen with respect to the texture of the material [40-47].

The Fatemi-Socie and Jiang criteria provided reasonable life predictions for the AZ31B Mg alloy. However, it should be noticed that most of the existing fatigue models including those evaluated in the current work were designed for isotropic materials and polycrystalline materials with deformation dominated by dislocation slips. For conventional materials, intergranular cracking and transgranular cracking along the slip lines are the primary cracking behavior under cyclic loading. For the $\mathrm{Mg}$ and $\mathrm{Mg}$ alloys, microcracking may also occur on the twin boundaries in addition to these two cracking modes [48,49]. Because of the additional deformation mechanisms in $\mathrm{Mg}$ and $\mathrm{Mg}$ alloys, fatigue damage due to twinning-detwinning and due to the interaction between dislocation slips and twinning-detwinning is not well understood and requires 
further studies. An understanding of the fatigue damage resulted from twinning-detwinning will help fatigue modeling of Mg alloys.

To consider the material anisotropy, comprehensive experimental studies should be conducted to understand the influence of the material texture on the fatigue behavior of $\mathrm{Mg}$ alloys. Experiments for different orientations of wrought $\mathrm{Mg}$ alloys are an avenue for such a purpose. In addition, the material anisotropy is dependent not only on the material process prior to the experiments, which forms the initial texture, but also on loading history. For example, an initial basal texture $\mathrm{Mg}$ alloy becomes $c$-textured after an application of a large compressive strain in the extrusion direction of an extruded $\mathrm{Mg}$ alloy [36,50]. The evolving nature of the material texture with loading history is a characteristic of $\mathrm{Mg}$ and $\mathrm{Mg}$ alloys and is a challenge in $\mathrm{Mg}$ research.

The Fatemi-Socie and Jiang criteria can serve as the point of departure for the development of fatigue models for $\mathrm{Mg}$ alloys due to their reasonable predictions of fatigue life and cracking behavior. Generalization of fatigue criteria designed for isotropic materials to anisotropic materials can be carried out with orientation-or texture-dependent material constants. For the Jiang criterion, it is possible that a single set of constants suffices for life prediction of a wrought $\mathrm{Mg}$ alloy. This possibility is motivated by a study on pure polycrystalline copper [51], which indicated that a single set of constants could be used to correlate all the experimental results obtained from the material with different textures and grain sizes. An advantage of such an approach is that it requires a reduced amount of experimental work for the determination of the material constants.

Fatigue lives of steels can be reasonably predicted using a critical plane approach when accurate stress-strain response is used as input but early cracking behavior is more difficult to predict [31]. This work indicates that this conclusion holds true for Mg alloys. For an assessment of a multiaxial fatigue criterion, often the stress-strain response directly determined from the experiment is used as input. For a structure, however, an accurate determination of the stress-strain response is usually difficult. This is especially true for Mg alloys because of the difficulty in modeling the stressstrain relation under cyclic loading. In the last few years, twinning and detwinning were incorporated into cyclic plastic models [52-54]. However, a realistic and accurate constitutive relation suitable for $\mathrm{Mg}$ alloys under general multiaxial cyclic loading requires further explorations of the micromechanisms of cyclic deformation of the material and the resulting fatigue damage.

\section{Conclusions}

The feasibility of using three existing critical plane approaches for the predictions of the fatigue behavior of an extruded AZ31B Mg alloy was investigated. Both the cracking behavior and the fatigue life of the material under a variety of axial-torsion loading conditions were considered in the evaluation. The Smith-Watson-Topper (SWT) criterion failed to correlate the tensioncompression and torsion baseline data. The Fatemi-Socie criterion yielded a good correlation of the fatigue lives, but a less satisfactory prediction of the cracking orientations. The undesirable correlation of the observed cracking angles with the predictions by the SWT and Fatemi-Socie criteria is attributed to the mixed cracking behavior observed on the material. The Jiang criterion 
provided reasonable fatigue life predictions and a good correlation of the cracking directions. Systematic and well-designed fatigue experiments should be conducted to understand the influence of material anisotropy on the fatigue behavior of $\mathrm{Mg}$ alloys and the role twinning-detwinning plays in fatigue damage.

\section{Acknowledgments}

Fábio Castro is grateful for the support provided by CAPES - Brazil (BEX 6715/14-1). Yanyao Jiang acknowledges support from the National Science Foundation (CMMI-1462885).

\section{References}

[1] Advances in wrought magnesium alloys: Fundamentals of processing, properties and applications. Publisher: Woodhead Publishing, Editors: Bettles C, Barnett M; 2012.

[2] Gaines L, Cuenca R, Stodolsky F, Wu S. Potential automotive uses of wrought magnesium alloys, Automotive Technology Development Conference, Detroit, Michigan; 1996.

[3] Frost FH, Eliezer D, Aghion E. The science, technology and applications of magnesium. JOM 1998;50(9):30-34.

[4] Bettles C, Gibson M. Current wrought magnesium alloys: strengths and weaknesses. JOM 2005;57:46-9.

[5] Sajuri ZB, Miyashita Y, Hosokai Y, Mutoh Y. Effects of Mn content and texture on fatigue properties of as-cast and extruded AZ61 magnesium alloys. Int J Mech Sci 2008;48:198-209.

[6] Zúberová Z, Kunz L, Lamark TT, Estrin Y, Janeĉek M. Fatigue and tensile behavior of cast, hot-rolled, and severely plastically deformed AZ31 magnesium alloy. Metall Mater Trans A 2007;38:1934-40.

[7] Lin XZ, Chen DL. Strain controlled cyclic deformation behavior of an extruded magnesium alloy. Mater Sci Eng A. 2008; 496: 106-113.

[8] Huppmann M, Lentz M, Brömmelhoff K, Reimers W. Fatigue properties of the hot extruded magnesium alloy AZ31. Mater Sci Eng A. 2010; 527: 5514-5521.

[9] Yu Q, Zhang J, Jiang Y, Li Q. Effect of strain ratio on cyclic deformation and fatigue of extruded AZ61 A magnesium alloy. Int J Fatigue 2012;44:225-33.

[10] Chen G, Lu L, Cui Y, Xing R, Gao H, Chen X. Ratcheting and low-cycle fatigue characterizations of extruded AZ31B Mg alloy with and without corrosive environment. Int J Fatigue 2015;80:364-71.

[11] Xiong Y, Yu Q, Jiang Y. Cyclic deformation and fatigue of extruded AZ31B magnesium alloy under different strain ratios. Mater Sci Eng A. 2016; 649:93-103.

[12] Bentachfine S. Etude en fatigue oligocyclique multiaxiale en phase et hors phase d'un alliage de magnésium-lithium. Thèse de Doctorat, Université de Metz, Metz, France, 1993.

[13] Bentachfine S, Pluvinage G, Toth LS, Azari Z. Biaxial low cycle fatigue under nonproportional loading of a magnesium-lithium alloy. Eng Fract Mech 1996;54:513-22. 
[14] Yu Q, Zhang JX, Jiang YY, Li QZ. Multiaxial fatigue of extruded AZ61 A magnesium alloy. Int J Fatigue 2011;33:437-47.

[15] Xiong Y, Yu Q, Jiang Y. Multiaxial fatigue of extruded AZ31B magnesium alloy. Mater Sci Eng A 2012;546:119-28.

[16] Albinmousa J, Jahed H, Lambert S. Cyclic behaviour of wrought magnesium alloy under multiaxial load. Int J Fatigue 2011;33:1127-39.

[17] Albinmousa J, Jahed H. Multiaxial effects on LCF behaviour and fatigue failure of AZ31B magnesium extrusion. Int J Fatigue 2014;67:103-16.

[18] Jiang Y, Sehitoglu H. Fatigue and stress analysis of rolling contact. Report no. 161, UILUENG 92-3602. College of Engineering, University of Illinois at Urbana-Champaign; 1992.

[19] Fatemi A, Socie DF. A critical plane approach to multiaxial fatigue damage including out-ofphase loading. Fatigue Fract Eng Mater Struct 1988;11:149-65.

[20] Jiang Y. A fatigue criterion for general multiaxial loading. Fatigue Fract Eng Mater Struct 2000;20:19-32.

[21] Jahed H, Varvani-Farahani A. Upper and lower fatigue life limits model using energy-based fatigue properties. Int J Fatigue 2006;28:467-73.

[22] Socie DF. Multiaxial fatigue damage models. ASME J Eng Mater Technol 1987;109:293-98.

[23] Leese GE, Socie DF. Multiaxial fatigue: analysis and experiments. SAE AE-14;1989.

[24] Socie DF. Critical plane approaches for multiaxial fatigue damage assessment. In: McDowell DL, Ellis R, editors. Advances in multiaxial fatigue, ASTM STP 1191. Philadelphia; 1993, p. 7-36.

[25] You BR, Lee SB. A critical review on multiaxial fatigue assessments of metal. Int J Fatigue 1996;18(4):235-44.

[26] Papadopoulos IV. A comparative study of multiaxial high-cycle fatigue criteria for metals. Int J Fatigue 1997;19:219-35.

[27] Socie DF, Marquis GB. Multiaxial fatigue. Warendale, PA: SAE International; 2000, ISBN 0-7680-0453-5.

[28] Fatemi A, Shamsaei N. Multiaxial fatigue: An overview and some approximation models for life estimation. Int J Fatigue 2011;33:948-58.

[29] Kim KS, Park JC, Lee JW. Multiaxial fatigue under variable amplitude loads. ASME J Eng Mater Technol 1999;121:286-293.

[30] Kim KS, Lee BL, Park JC. Biaxial fatigue of stainless steel 304 under irregular loading. ASTM STP 1389, Halford GR and Gallagher JP, Eds.; 2000 , p. 79-93.

[31] Jiang Y, Hertel O, Vormwald M. An experimental evaluation of three critical plane multiaxial fatigue criteria. Int J Fatigue 2007;29:1490-502.

[32] Zhao T, Jiang Y. Fatigue of 7075-T651 aluminum alloy. Int J Fatigue 2008;30:834-49.

[33] Kalnaus S, Jiang Y. Fatigue of AL6XN stainless steel. ASME J Eng Mater Technol 2008;130(3):031013.

[34] Gao Z, Zhao T, Wang X, Jiang Y. Multiaxial fatigue of 16MnR steel. ASME J Press Vess Technol 2009;131(2):021403. 
[35] Smith KN, Watson P, Topper TH. A stress-strain function for the fatigue of metals. J Mater 1970;5(4):767-78.

[36] Dong S, Jiang Y, Dong J, Wang F, Ding W. Cyclic deformation and fatigue of extruded ZK60 magnesium alloy with aging effects. Mater Sci Eng A 2014;615:262-72.

[37] Xiong Y, Jiang Y. Fatigue of ZK60 magnesium alloy under uniaxial loading. Int J Fatigue 2014;64:74-83.

[38] McDowell DL, Dunne FPE. Microstructure-sensitive computational modeling of fatigue crack formation. Int J Fatigue 2010;32(9):1521-1542.

[39] Castelluccio GM, McDowell DL. Microstructure-sensitive small fatigue crack growth assessment: Effect of strain ratio, multiaxial strain state, and geometric discontinuities. Int J Fatigue 2016;82:521-529.

[40] Wu L, Agnew SR, Ren Y, Brown DW, Clausen B, Stoica GM, et al. The effects of texture and extension twinning on the low-cycle fatigue behavior of a rolled magnesium alloy, AZ31B. Mater Sci Eng A 2010;527:7057-67.

[41] Park SH, Hong S-G, Bang W, Lee CS. Effect of anisotropy on the low-cycle fatigue behavior of rolled AZ31 magnesium alloy. Mater Sci Eng A. 2010;527:417-23.

[42] Sajuri ZB, Miyashita Y, Hosokai Y, Mutoh Y. Effects of Mn content and texture on fatigue properties of as-cast and extruded AZ61 magnesium alloys. Int J Mech Sci 2006;48:198-209.

[43] Ishihara S, Nan Z, Goshima T. Effect of microstructure on fatigue behavior of AZ31 magnesium alloy. Mater Sci Eng A 2007;468-470:214-22.

[44] Lv F, Yang F, Duan QQ, Luo TJ, Yang YS, Li SX, Zhang ZF. Tensile and low-cycle fatigue properties of $\mathrm{Mg}-2.8 \% \mathrm{Al}-1.1 \% \mathrm{Zn}-0.4 \% \mathrm{Mn}$ alloy along the transverse and rolling directions. Scripta Mater 2009;61:887-90.

[45] Lv F, Yang F, Duan QQ, Yang YS, Wu SD, Li SX, Zhang ZF. Fatigue properties of rolled magnesium alloy (AZ31) sheet: Influence of specimen orientation. Int J Fatigue 2011;33:67282.

[46] Ishihara S, Taneguchi S, Shibata H, Goshima T, Saiki A. Anisotropy of the fatigue behavior of extruded and rolled magnesium alloys. Int J Fatigue 2013;50:94-100.

[47] Jordon JB, Brown HR, Haitham El Kadiri H, Kistler HM, Lett RL, Baird JC, Luo AA. Investigation of fatigue anisotropy in an extruded magnesium alloy. Int J Fatigue 2013;51:814.

[48] Wang F, Dong J, Feng M, Sun J, Ding W, Jiang J. A study of fatigue damage development in extruded Mg-Gd-Y magnesium alloy. Mater Sci Eng A 2014;589:209-16.

[49] Yu Q, Zhang J, Jiang Y. Fatigue damage development in pure polycrystalline magnesium under cyclic tension-compression loading. Mater Sci Eng A 2011;528:7816-26.

[50] Xiong X, Yu Q, Jiang Y. An experimental study of cyclic plastic deformation of extruded ZK60 magnesium alloy under uniaxial loading at room temperature. Int J Plasticity 2014;53:107-24.

[51] Zhang J, Jiang Y. Fatigue of polycrystalline copper with different grain sizes and texture. Int J Plasticity 2006;22:536-56. 
[52] Wang $\mathrm{H}$, Wu P, Tomé $\mathrm{C}$, Wang J. A constitutive model of twinning and detwinning for hexagonal close packed polycrystals. Mater Sci Eng A 2012;555:93-8.

[53] Wang H, Wu P, Wang J, Tomé C. A crystal plasticity model for hexagonal close packed (HCP) crystals including twinning and de-twinning mechanisms. Int J Plasticity 2013;49:3652.

[54] Wu W, Qiao H, An K, Guo X, Wu P, Liaw PK. Investigation of deformation dynamics in a wrought magnesium alloy. Int J Plasticity 2014;62:105-20. 